\title{
WOUND HEALING AROUND AND WITHIN SAPHENOUS VEIN BYPASS GRAFTS
}

James E. O'Brien, Jr., MD

Yi Shi, MD, $\mathrm{PhD}^{\mathrm{b}}$

Ali Fard, $M D^{b}$

Thomas Bauer, $\mathrm{MD}^{\mathrm{a}}$

Andrew Zalewski, $\mathrm{MD}^{\mathrm{b}}$

John D. Mannion, $\mathrm{MD}^{\mathrm{a}}$
Background: Myofibroblasts are a prominent cell type in wound healing. The goal of this study was to examine the extent to which myofibroblasts contribute to structural changes in saphenous vein bypass grafts. Methods and results: Control veins and reversed saphenous vein bypass conduits of porcine carotid arteries were examined 2 to 4,7 to 14 , and 30 to 90 days after surgery with immunohistochemical markers of cellular proliferation (proliferating cell nuclear antigen), cytoskeletal protein production $(\alpha-$ smooth muscle actin and desmin), and histochemistry (Verhoeff's stain). Control veins demonstrated an extremely low level of cellular proliferation and no evidence of myofibroblasts in the adventitia, media, or intima. After bypass grafting, cellular proliferation was followed by myofibroblast formation, which occurred in the perivascular area and within the media. This was evidenced by a dense, but transient, expression of $\alpha$-smooth muscle actin and a variable expression of desmin at 1 to 2 weeks, and with a significant increase in collagenous tissue by 1 to 3 months. Major cytoskeletal protein changes also occurred in the intima, with the appearence of $\alpha$-smooth muscle actin positive cells at 7 to 14 days. $\alpha$-Smooth muscle actin was still present in the neointima at 1 to 3 months, which is compatible with a persistent myofibroblast formation. Conclusion: Myofibroblast formation occurs around and within saphenous veins after bypass grafting. This phenomenon is associated with significant remodeling of the vein grafts. The histologic changes are strikingly similar to events that occur during wound healing and may have implications for the development of neointimal hyperplasia and late vein graft disease. ( $J$ Thorac Cardiovasc Surg 1997;114:38-45)
In response to trauma, tissues undergo a repair process in which fibroblasts are changed into myofibroblasts. These cells rapidly proliferate, deposit extracellular matrix, ${ }^{1,2}$ and are responsible for wound contraction. ${ }^{3,4} \mathrm{We}^{5,6}$ have recently reported that after a deep coronary artery injury, adventitial fibroblasts acquire characteristics of myofibroblasts

From the Cardiovascular Research Center, Departments of Surgery $^{a}$ (Division of Cardiothoracic Surgery) and Medicine ${ }^{b}$ (Division of Cardiology), Jefferson Medical College, Philadelphia, $\mathrm{Pa}$.

Supported in part by the National Institutes of Health (grant HL-44150).

Received for publication May 13, 1996; revisions requested August 9, 1996; revisions received Oct. 1, 1996; accepted for publication Jan. 30, 1997.

Address for reprints: John D. Mannion, Suite 607 College, Jefferson Medical College, 1025 Walnut St., Philadelphia, PA 19107.

Copyright (C) 1997 by Mosby-Year Book, Inc.

0022-5223/97 $\$ 5.00+0 \quad \mathbf{1 2 / 1 / 8 0 7 7 5}$ and contribute to remodeling of the entire vessel wall. These findings have raised the possibility that similar activation of vascular and perivascular fibroblasts, rather than medial smooth muscle cells, may be responsible for vascular remodeling after vein grafting.

The concept of vascular remodeling and the mechanisms responsible for it are important. The observation that the geometry of arteries can change in response to alterations in the local environment has long been known to surgeons. ${ }^{7}$ Recently, different types of vascular remodeling have been described. In response to slowly progressive atherosclerotic lesions, an artery can dilate and maintain an adequate lumen size. ${ }^{8}$ This compensatory response may be significantly diminished or even reversed in advanced atherosclerosis ${ }^{8}$ and in vascular repair, ${ }^{9,10}$ thereby contributing to the development of arterial stenoses. This "lack of dilatation" has also recently been reported in human saphenous vein grafts with intravascular ultrasonography, ${ }^{11}$ al- 
though the exact mechanisms for this phenomenon are unknown. The primary purpose of this study was to examine the adventitia and perivascular area of saphenous veins with histochemical methods for myofibroblast formation to determine whether these cells contribute to unfavorable remodeling of vein graft conduits.

In this study, we have shown that the changes typical of wound healing, most notably myofibroblast formation, occur around arterialized saphenous vein grafts. The contractile and synthetic properties of myofibroblasts may contribute to the reported lack of compensatory dilatation. In addition, we have noted that a similar wound healing process occurs within the media and possibly even in the neointima of saphenous vein grafts. These observations may be important, because the early structural changes that occur in these compartments after grafting may lead to undesirable late vein graft degeneration. ${ }^{12-15}$

\section{Methods}

Animal preparation. Domestic pigs $(n=17$, weight 25 to $35 \mathrm{~kg}$ ) were premedicated with aspirin $(650 \mathrm{mg}$ by mouth) 1 day before the procedure. They were sedated with intramuscular ketamine $(20 \mathrm{mg} / \mathrm{kg})$ and xylazine $(4$ $\mathrm{mg} / \mathrm{kg}$ ) and anesthetized with thiopental sodium (7 to 10 $\mathrm{mg} / \mathrm{kg}$ ). Anesthesia was maintained after endotracheal intubation with inhaled halothane $(0.75 \%)$.

With the use of sterile surgical techniques, the long saphenous vein was harvested from both thighs via a longitudinal skin incision directly above the vein. Side branches were secured with fine silk ties or 7-0 polypropylene sutures. The veins were placed briefly in a bath of sterile saline solution containing heparin $(5$ units $/ \mathrm{ml})$ and papaverine $(0.7 \mathrm{mg} / \mathrm{ml})$ at room temperature.

The surgical model was adapted from Angelini, ${ }^{16}$ Violaris, ${ }^{17}$ and their associates. A midline neck incision was made, through which both carotid arteries were dissected free. Heparin (150 to 300 units $/ \mathrm{kg}$ ) was given intravenously, proximal and distal control of the artery was obtained, and a 1 to $2 \mathrm{~cm}$ section of artery was excised. The reversed saphenous vein was interposed between the beveled edges of the right carotid artery, followed by the left, with the use of a continuous 8-0 polypropylene suture. Hemostasis was achieved, and the incision was closed in layers. The animals were permitted to recover and were killed 2 to $4(n=5), 7$ to $14(n=7)$, or 28 to 90 days $(n=5)$ after the operation. The animals were cared for in accordance with the "Principles of Laboratory Animal Care" formulated by the National Society of Medical Research and the "Guide for the Care and Use of Laboratory Animals" prepared by the Institute of Laboratory Animal Resources published by the National Institutes of Health (NIH publication No. 86-23, revised 1985).

Vessel preparation. When the animals were put to death, the neck incision was opened and the carotid artery distal to the graft was divided to demonstrate pulsatile blood flow and to ensure patency of the vessel. The carotid artery, interposition vein graft, and surrounding tissue were then harvested en bloc. The vessels were rinsed in phosphate-buffered saline solution and placed in HistoChoice tissue fixative (Amresco, Ohio), sectioned into $3 \mathrm{~mm}$ segments, processed (Tissue-Tek VIP processor, Miles Inc.), embedded in paraffin, and cut into $5 \mu \mathrm{m}$ thick sections.

For assessment of vascular architecture, Verhoeff's stain for elastic tissue was used. The external elastic lamina was identified as a thick layer of elastic fibers, immediately adjacent to the media. Adventitia was defined as external to the inner layer of the external elastic lamina, extending to the outer edge of the external elastic lamina. The periadventitial space was defined as external to the elastic fibers in the external lamina. By 7 days after the injury, the periadventitia was adherent to the adventitia. The term perivascular space is used to define the adventitia and periadventitia combined.

Immunohistochemistry. The VECTASTAIN Elite $A B C$ system (Vector Laboratories) was used for immunohistochemistry. Sections were deparaffinized, incubated with $0.6 \%$ hydrogen peroxide in methanol for 30 minutes, and blocked with 5\% horse serum. After being washed in phosphate-buffered saline solution, the sections were incubated with primary antibodies for 1 hour at room temperature or overnight at $4^{\circ} \mathrm{C}$ in a moisture chamber. The following primary antibodies were used: monoclonal mouse PC10 antibody recognizing proliferating cell nuclear antigen (PCNA, 1:200, DAKO), monoclonal mouse $1 \mathrm{~A} 4$ antibody recognizing $\alpha$-smooth muscle actin ( $\alpha$-SM actin, 1:100, Sigma Diagnostics), and monoclonal mouse DE-R-11 antibody recognizing intermediate filament desmin (1:50, Novocastra). Afterward, slides were washed and incubated with biotinylated secondary horse antimouse antibodies (1:2000, Vector Laboratories) for 1 hour. They were visualized with DAB substrate (Vector Laboratories), followed by a counterstain with Gill's hematoxylin stain (Sigma Diagnostics). Negative controls were carried out with the use of nonimmune serum instead of primary antibody.

Proliferative index. Cell proliferation was quantified with the use of the PCNA-stained sections, and quantifications were performed for each vessel. Four regions in each layer of the vessel were randomly chosen for quantitative analysis. At least 800 nuclei per vessel were counted. The extent of proliferation was expressed as the percent of PCNA-positive nuclei (proliferative index).

Morphometric analyses. Sections of the vessel stained with Verhoeff's stain were used for the morphometric analyses. The medial and neointimal thickness for each vessel was measured with the use of a computerized imaging system (Advanced Imaging Concepts, Inc.). Measurements were taken across the radius of the vessels at four locations per vessel (at the 12,3,6, and 9 o'clock positions). The measurements for each vessel were then combined and reported as a mean for that vessel.

Statistical analysis. All data are expressed as mean \pm standard error of the mean. The statistical significance for the proliferative indices and the morphometric measurements was determined with the use of the one-way 

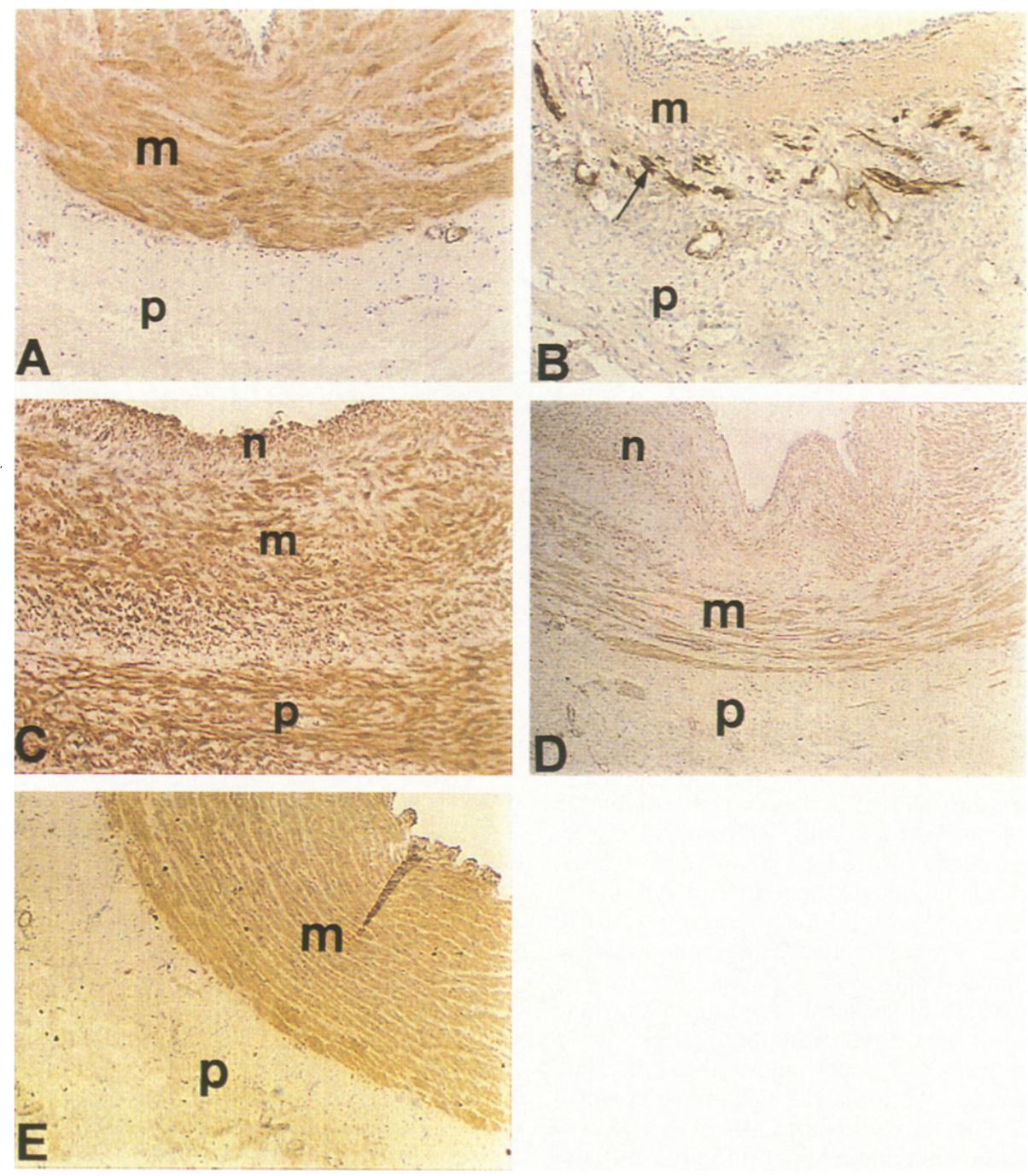

Fig. 1. Photomicrograph of $\alpha$-SM actin stains in the control vein (A) and 3 days (B), 14 days (C), and 90 days (D) after saphenous vein graft arterializations. E, $\alpha$-SM actin stain of arterial section at 30 days. $\alpha$-SM actin stains brown. A, Control veins demonstrate thin intima and thick media, which is strongly $\alpha$-SM actin positive. The perivascular space is negative for $\alpha$-SM actin. Note bundles of nonmuscle cells in the media. $\mathbf{B}$, The inner third of the media is acellular, with remnants of $\alpha$-SM actin positive cells in the outer media. This represents extensive destruction of medial smooth muscle cells. C, Note the increase in intimal thickness. Neointima, media, and adventitia are now strongly positive for $\alpha$-SM actin. D, The intima remains positive for $\alpha$-SM actin. Note, however, the increase in $\alpha$-SM actin negative cells in the media. $\mathbf{E}$, $\alpha$-SM actin stain of adjacent arterial section 30 days after the operation. Note excellent preservation of the media, with no evidence of nonmuscle cells. $n$, Neointima; $m$, media; $p$, periadventitia; arrow, remnants of smooth muscle cells in media. (Original magnifications: $A, B, C$, and $E, \times 100 ; D, \times 40$.)

analysis of variance. A $p$ value less than 0.05 was considered significant.

\section{Results}

Myofibroblast formation in perivascular area of venous grafts. To examine the formation of myofibroblasts after saphenous vein grafting, we assessed temporal changes in the expression of $\alpha$-SM actin (Fig. 1) and desmin (Fig. 2). Control veins contained no evidence of perivascular $\alpha$-SM actin (Fig. 1, $A$ ). Two to 4 days after the operation the periadventitia was generally not yet adherent, but $\alpha$-SM actin appeared faintly in a few areas of adherent tissue (Fig. 1, B). By 7 to 14 days after the operation, 


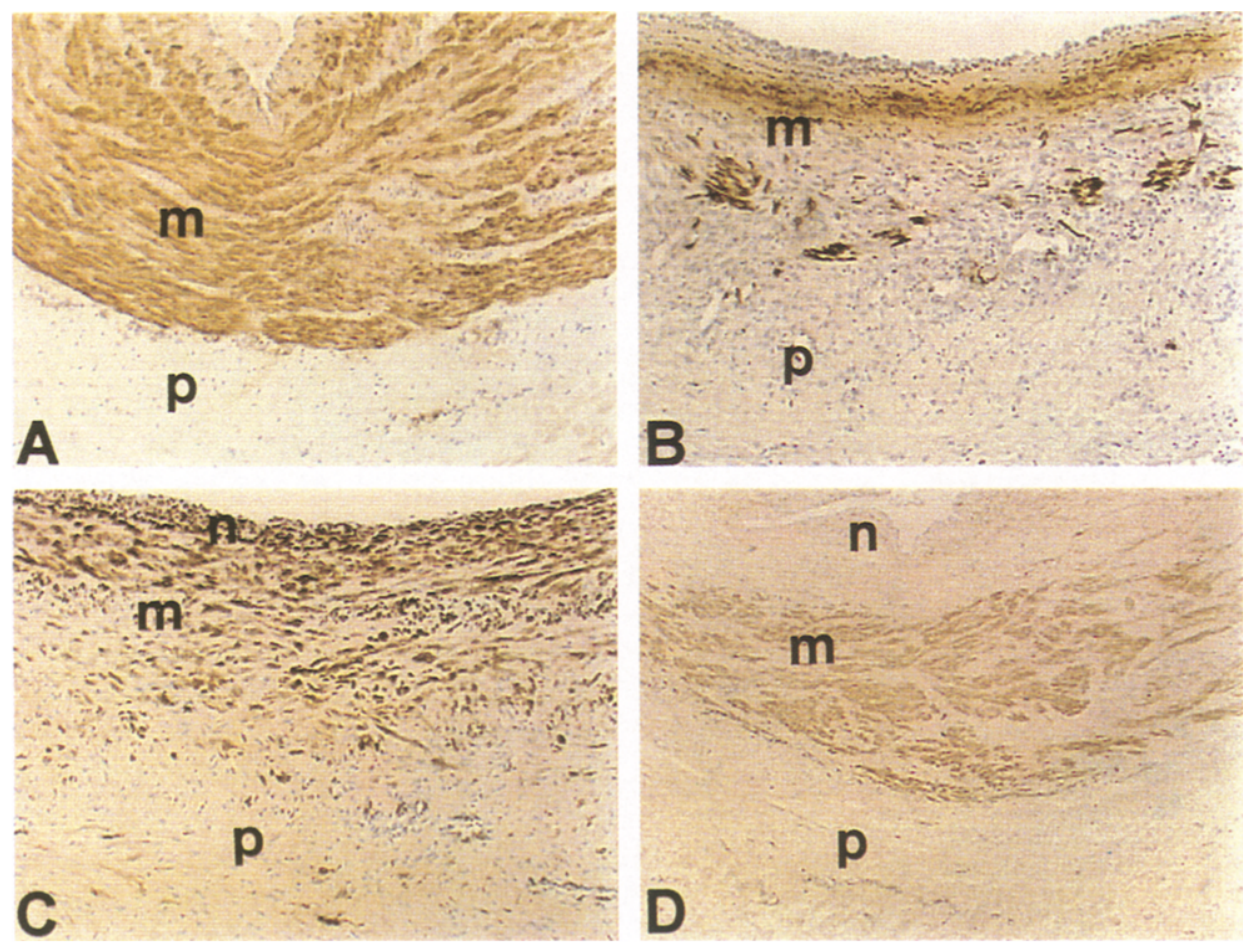

Fig. 2. Photomicrograph of desmin stains in the control vein (A) and at 3 days (B), 14 days (C), and 90 days (D) after saphenous vein graft arterialization. Desmin staining cells are brown. A, Control veins demonstrate dense desmin staining of the media, corresponding to $\alpha$-SM actin stains. Intima and periadventitia are negative for desmin. B, Only a few cells in the media now contain desmin, consistent with the loss of medial smooth muscle cells. C, Intima, media, and periadventitia now contain expression of desmin, with a strong gradient between the intima and periadventitia. Desmin stains in the media and periadventitia are much less strong than $\alpha$-SM actin stains. D, Desmin stain is now apparent only in a relatively well-preserved media. Note, however, thick non-desmin staining bundles in the media. Transient appearance and later disappearance of desmin is typical of myofibroblasts. $n$, Neointima; $m$, media; $p$, periadventitia. (Original magnifications: $A, B$, and $C, \times 100 ; D, \times 40$.)

hypercellular perivascular regions stained densely positive for $\alpha$-SM actin (Fig. 1,C). This change was transient, however, because by 28 to 90 days, staining for $\alpha$-SM actin was limited (Fig. 1, D), except for the vasa vasorum. The temporary appearance of cells positive for $\alpha$-SM actin is consistent with myofibroblast formation. ${ }^{2,5,18}$ Adjacent arterial sections also showed significant myofibroblast formation in the perivascular area (figures not shown).

The expression of desmin followed a transient pattern similar to that of $\alpha$-SM actin (Fig. 2), although its expression was less intense. As shown in Fig. 2, control adventitia contained no evidence of desmin in the perivascular zone. Although desmin expression had increased slightly by 7 to 14 days, the increase was far less pronounced than that noted for $\alpha$-SM actin. By 28 days, desmin had disappeared from the perivascular space. A transient, partial expression of desmin is compatible with myofibroblast formation.

Myofibroblast formation was associated with active cellular proliferation. The percentage of proliferating cells in all vessel layers was low in unoperated control veins $(<1 \%)$. One to 2 weeks after the operation, the percentage of proliferating cells in the perivascular area was $34 \% \pm 5 \%$ (Fig. 3). Likewise, arterial sections also contained a high proliferative rate in the perivascular area $(22 \% \pm$ $3 \%)$.

Myofibroblast formation in the media of saphenous vein grafts. The cytoskeletal protein characteristics of the media also changed dramatically with time. In situ saphenous veins exhibited a thick muscular media, which stained strongly positive for both $\alpha$-SM actin and desmin. Thus the media was composed predominantly of smooth muscle cells, 


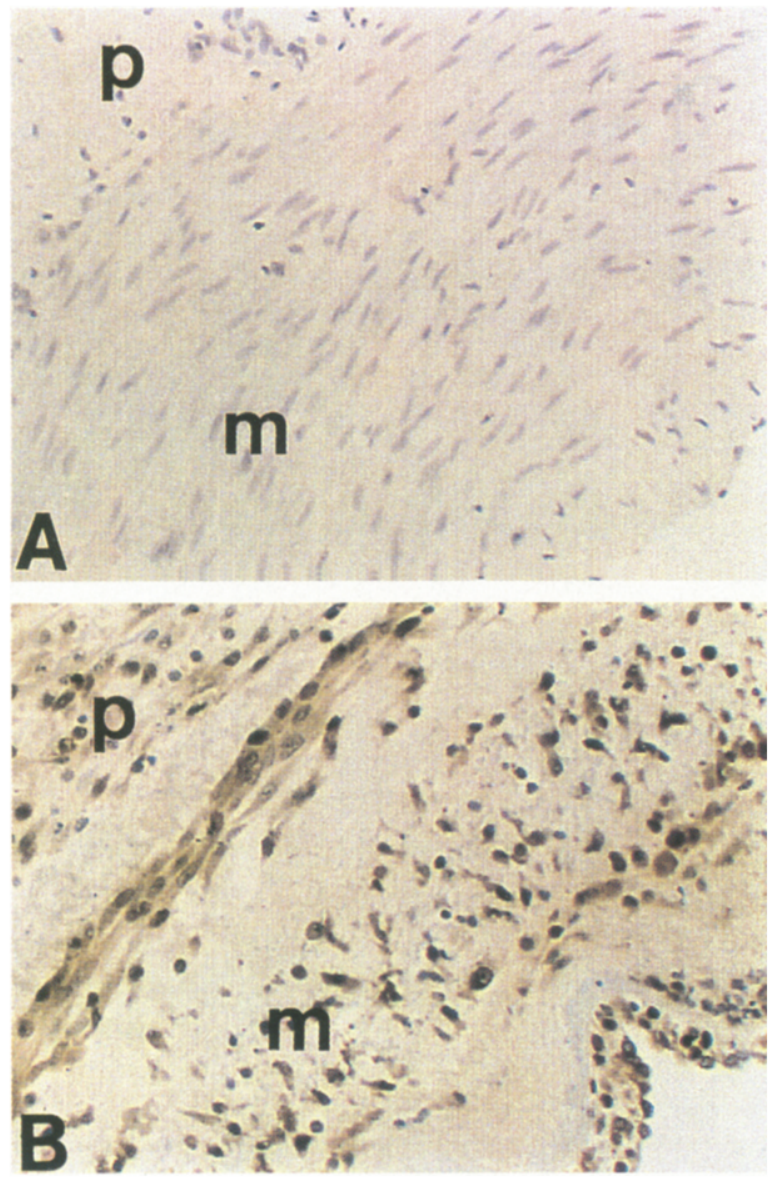

Fig. 3. Photomicrograph of PCNA stains in control vein (A) and 14-day (B) saphenous vein grafts. Nucleus of cell stains brown in PCNA positive cells. A, Control veins show no evidence of cellular proliferation in the periadventitia, media, or intima. B, Evidence of transmural cellular proliferation. $m$, Media; $p$, periadventitia. (Original magnifications $\times 200$.)

although medial fibroblasts were present (Figs. 1, $A$ and $2, A$ ). By 2 to 4 days after grafting, the percentage of medial muscle cells had decreased markedly, often with only thin strands of medial smooth muscle cells remaining (Figs. 1, $B$ and 2, $B$ ). The paucity of smooth muscle cells suggests medial necrosis. By 7 to 14 days after the operation, the media again became strongly positive for $\alpha$-SM actin, but these new cells did not resemble typical smooth muscle cells, because they incompletely expressed desmin (Figs. 1, C and 2,C). By 1 to 3 months after the operation, further changes in the histochemical markers had occurred: the media contained only small bundles of typical smooth muscle cells ( $\alpha$-SM actin, desmin positive) interspersed among $\alpha$-SM actin negative, desmin negative cells (Figs. 1, D and $2, D$ ). This pattern was opposite that of control veins, wherein typical smooth muscle cells predominated. These dynamic changes in the composition of the media, in particular the transient reappearance of $\alpha$-SM actin associated with partial desmin expression, suggest that myofibroblasts also formed within the media. The fact that similar changes took place within the perivascular area, with an identical temporal sequence, strengthens this argument. The active changes in the media are reflected in the proliferative rate at 2 weeks, with $21 \% \pm 7 \%$ of cells positive for PCNA (Fig. 3).

In contrast, the adjacent arterial media demonstrated no significant modulation of $\alpha$-SM actin and desmin immunostaining (figures not shown). Thus myofibroblast formation was prominent in the perivascular area of both adjacent arterial sections and the venous conduits, but was apparent only within the media of the venous conduits, and was not prominent within the media of the artery. Furthermore, the intactness of the media in adjacent arterial sections was reflected by the low proliferative rate of the media, with only $6 \% \pm 2 \%$ of cells positive for PCNA.

Cytoskeletal changes in the intima of venous grafts. The cytoskeletal protein characteristics of the neointima differed from those in the perivascular area and in the media. At 7 to 14 days, the neointima was characterized by the same dense $\alpha$-SM actin expression, but with a more intense desmin immunostaining than that seen in the media and adventitia (Figs. 2, $C$ and 3, C). A decreasing gradient of desmin expression from the intima to the adventitia is evident in Fig. 2, C. In addition, and again in contrast to the perivascular area and media, 1 to 3 months after the operation the neointimal cells remained strongly $\alpha$-SM actin positive.

Remodeling changes after saphenous vein grafting. The consequences of myofibroblast formation on the remodeling of the saphenous vein grafts are seen in Fig. 4. At 3 months, dense deposition of collagenous tissue could be seen in the perivascular space, with abundant vasa vasorum formation. In addition, extensive collagen formation was apparent in the media and neointima. This was associated with an increase in the size of the media $(0.18 \pm 0.01$ $\mathrm{mm}$ to $0.49 \pm 0.16 \mathrm{~mm}, p<0.01)$ and neointima $(0.08 \pm 0.04 \mathrm{~mm}$ to $0.60 \pm 0.30 \mathrm{~mm}, p<0.01)$ over the time course of the experiment. In fact, with Verhoeff's stain, the histologic appearance of the adventitia, media, and neointima was similar, sug- 

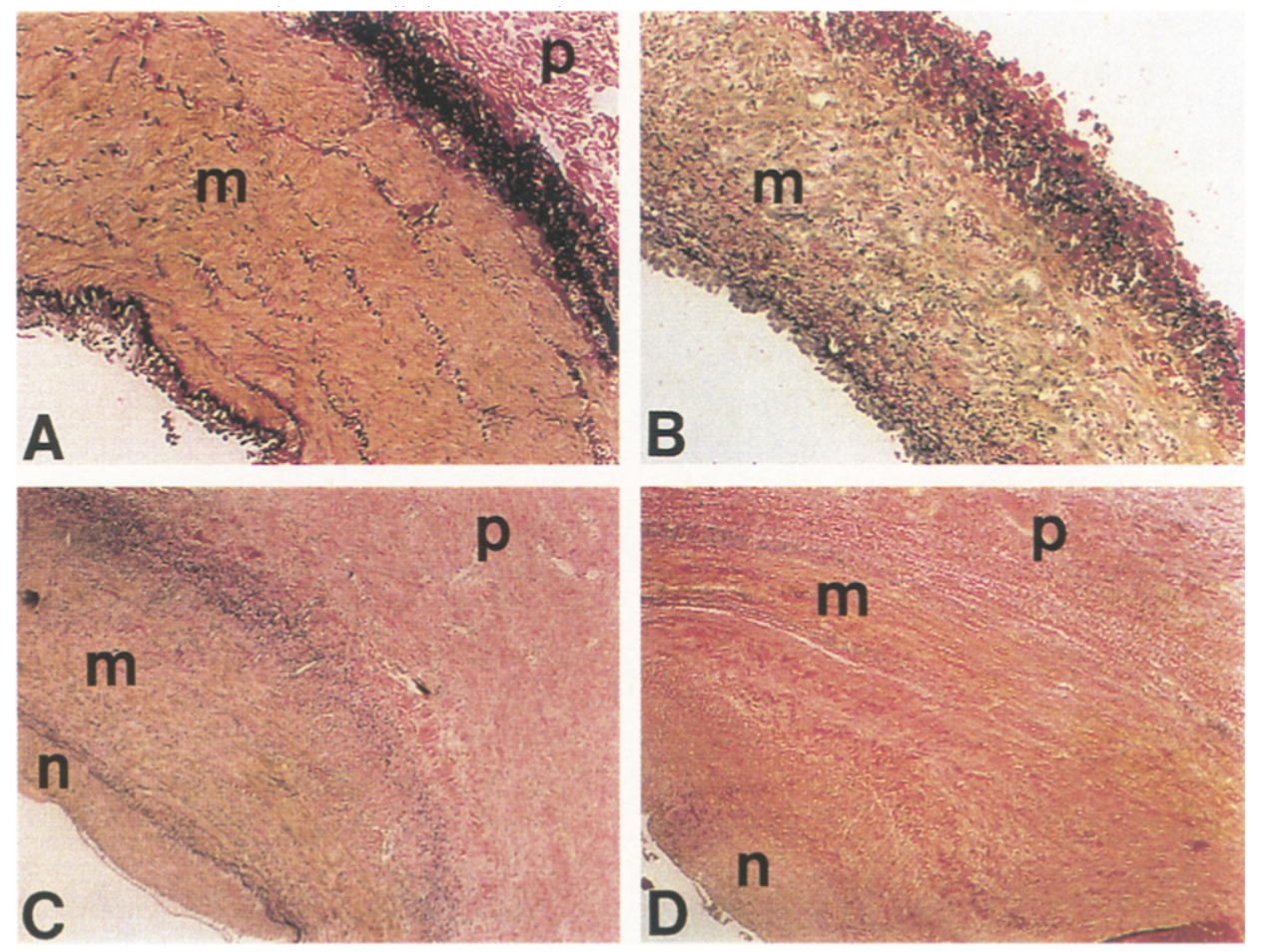

Fig. 4. Photomicrograph of Verhoeff's stains in control vein (A) and in 3-day (B), 14-day (C), and 90-day (D) saphenous vein grafts. A, Control veins demonstrate thin intima and thick, muscular media with few interspersed elastic adventitia. B, Note thin intima and edematous media, suggesting significant destruction of smooth muscle cells. The entire periadventitia of this specimen was removed at the original operation. $\mathbf{C}$, The increase in collagen-rich tissue in the periadventitia with numerous vasa vasorum is seen. Thickened media and neointima are apparent. D, Because of the remodeling of the perivascular zone and the wall of the vein graft, it is difficult to distinguish the three layers of vein wall. The periadventitia, media, and neointima are all rich in collagenous tissue. $n$, Neointima; $m$, media; $p$, periadventitia. (Original magnifications: $A, B$, and $C, \times 100 ; D, \times 40$.)

gesting concordant remodeling changes in the three compartments of the vein graft (Fig. 4).

\section{Discussion}

This study demonstrates that an active cellular proliferation occurs in the vein graft perivascular space, with fibroblasts transiently changing into myofibroblasts. This, in turn, is followed by a dense collagen deposition. Thus the perivascular area undergoes a typical process of wound healing. Furthermore, our findings suggest that myofibroblast formation extends deep into the saphenous vein wall, resulting in extensive early remodeling of the entire thickness of the vein graft. These early histologic changes in vein grafts may contribute to the development of late vein graft failure.

Wound healing in the perivascular space. Previous studies on the kinetics of cell proliferation after saphenous vein grafting have not specifically addressed the perivascular area. ${ }^{19,20}$ Such 'studies have generally been confined to the endothelium and the media. The high proliferative rate in the perivascular area seen here is consistent with a vigorous wound healing response.

Recent developments in the biology of wound healing led to an understanding of how perivascular myofibroblasts could affect vein graft patency. Wound healing involves early fibroblast proliferation (days 1 to 3 ), ${ }^{1,21}$ followed by active type I collagen and fibronectin production (days 4 to 6), followed in turn by cytoplasmic $\alpha$-SM actin fibril condensation (days 7 to 14). ${ }^{1,18}$ The appearance of stress fibers, a hallmark of myofibroblast formation, coincide with wound contraction. Thus myofibroblasts populate the wound, contribute to extracellular matrix production, but also permit the wound to contract. ${ }^{18}$ This response to injury, developed during evolution and demonstrated here, is necessary to 
close an open wound, but it also may result in the inability of the venous conduit to dilate with the growth of neointima or later atherosclerotic plaque. Although wound healing is necessary for recovery from surgical trauma, it remains to be determined whether modifications of this process might improve surgical outcomes.

Cytoskeletal protein changes in the media of a vein graft. This study yielded three important observations concerning myofibroblast formation and the vein graft media: First, there appears to be an early and sometimes extensive loss of medial smooth muscle cells. Second, at 1 to 2 weeks, cells consistent with a myofibroblast phenotype populate the media. Third, at later time points, there is considerable collagen deposition in the vein graft wall. These changes are consistent with the recently recognized synthetic properties of vascular myofibroblasts. ${ }^{5,22}$

To date, it has been assumed that undifferentiated vascular smooth muscle cells were responsible for vascular repair. ${ }^{23,24}$ After grafting, smooth muscle cells from the media have been thought to proliferate and migrate. However, recent data have questioned this assumption. Both arterial and saphenous vein media of the dog contain smooth muscle and "nonmuscle" cells, but the latter appear to have a higher capacity to proliferate. ${ }^{25}$ Histochemical data from the present study favor the concept that myofibroblasts participate in vein graft repair. The expected appearance of myofibroblasts in the perivascular space, which is a wound healing response to trauma, is paralleled by similar modifications in the media. The medial changes are not necessarily due to "synthetic" smooth muscle cells, because myofibroblast formation can plausibly explain the histologic changes. The distinction between a smooth muscle cell and a myofibroblast in vein graft histology is relevant if progress is to be made in modifying and improving the response of a vein graft to arterialization.

Cytoskeletal protein changes in the intima of a vein graft. In contrast to the perivascular area and media, the neointima has a sustained expression of $\alpha$-SM actin. Although sustained $\alpha$-SM actin expression is characteristic of smooth muscle cells, it can also be seen in myofibroblasts. ${ }^{26}$ The mechanism of sustained myofibroblast presence is unclear; however, the prolonged expression of potent growth factors and cytokines may play an important role. The appearance of vascular myofibroblasts has been associated with autocrine expression of transform- ing growth factor $-\beta^{1}$, which lasts longer in the neointima than in the adventitia. ${ }^{27}$

As this study confirms, a prominent aspect of vein graft remodeling is the appearance of a substantial neointima. The general belief has been that smooth muscle cells migrate from the media into the luminal surface and proliferate, as has been proposed after arterial injury. ${ }^{23,28-30}$ In the present study, the observation that the media becomes populated with myofibroblasts argues against the concept that smooth muscle cells are the only source of neointima. An interesting possibility is that myofibroblasts may migrate to the neointima, as had been noted after arterial injury. ${ }^{6}$ Further studies may expand the role of myofibroblasts concerning the formation of neointima in arterialized vein grafts.

Arterial reactions to surgical trauma. A comparison of the cytoskeletal protein characteristics of the vein grafts with arterial segments reveals important differences. First, no evidence can be found to support significant smooth muscle injury in the media of arterial sections. Second, myofibroblast formation occurs in the adventitia of the artery, but not in the media. Finally, significant neointimal formation is found only within a vein graft and not within arterial sections. It is conceivable that the differences between the histochemical changes of the arterial and venous media may provide an explanation for the improved patency of arterial grafts.

Limitations. This study defined changes in vein grafts over time. The same vein graft obviously could not be studied at serial time points. This could lead to possible error, in that vein graft injury during grafting would not be expected to be the same within the same vein graft or between animals. This study does suggest that when injury is present, including medial injury, a wound healing process is also present.

\section{Conclusion}

Cytoskeletal protein markers have been used to identify changes in fibroblasts of both vein grafts and arterial sections. Rapid fibroblast proliferation and myofibroblast formation around a saphenous graft are consistent with wound healing and may induce remodeling changes of the entire conduit. Therapy directed at modifying the fibroblast response to surgical trauma may affect undesirable fibrotic changes in the entire vein graft wall.

We thank Felicia Hayes and Dian Wang for their expert technical assistance. 


\section{REFERENCES}

1. Clark R. Regulation of fibroplasia in cutaneous wound repair. Am J Med Sci 1993;306:42-8.

2. Sappino AP, Schurch W, Gabbiani G. Differentiation repertoire of the fibroblastic cells: expression of cytoskeletal proteins as marker of phenotypic modulations. Lab Invest 1990;63:144-61.

3. Gabbiani G, Ryan GB, Majno G. Presence of modified fibroblasts in granulation tissue and their possible role in wound contraction. Experientia 1971;27:549.

4. Gabbiani G, Hirschel BJ, Ryan GB, Statkov PR, Majno G. Granulation tissue as a contractile organ: a study of structure and function. J Exp Med 1972;135:719.

5. Shi Y, Pieniek M, Fard A, O'Brien J, Mannion JD, Zalewski A. Adventitial remodeling following coronary arterial injury. Circulation 1996;93:3440-8.

6. Shi Y, O'Brien J, Fard A, Mannion JD, Zalewski A. Adventitia myofibroblasts contribute to neointimal formation in injured porcine coronary arteries. Circulation 1996;94:1655-64.

7. Holman E. Problems in the dynamics of blood flow. I. Condition controlling collateral ligation in the presence of an arteriovenous fistula, following the ligation of an artery. Surgery 1949;26:889-917.

8. Glagov S, Weisenberg E, Zarins CK, Stankunavicius R, Kolettis GJ. Compensatory enlargement of human atherosclerotic coronary arteries. N Engl J Med 1987;316:1371-5.

9. Kakuta T, Currier JW, Haudenschild CC, Ryan TJ, Faxon DP. Differences in compensatory vessel enlargement, not intimal formation, account for restenosis after angioplasty in the hypercholesterolemic rabbit model. Circulation 1994;89: 2809-15.

10. Post MJ, Borst C, Kuntz RE. The relative importance of arterial remodeling compared with intimal hyperplasia in lumen renarrowing after balloon angioplasty: a study in the normal rabbit and the hypercholesterolemic Yucatan micropig. Circulation 1994;89:2816-21.

11. Nishioka $T$, Luo $H$, Berglund $H$, et al. Absence of focal compensatory enlargement or constriction in diseased human coronary saphenous vein bypass grafts: an intravascular ultrasound study. Circulation 1996;93:683-90.

12. Clowes AW. Pathologic intimal hyperplasia as a response to vascular injury and reconstruction. In: Ruthorford RB, editor. Vascular surgery. 4th ed. Philadelphia: WB Saunders; 1995. pp. 285-95.

13. Clowes AW. Intimal hyperplasia and graft failure. Cardiovase Pathol 1993:3:179S-86S.

14. Dilley RJ, McGeachie JK, Prendergast FJ. A review of the histologic changes in vein-to-artery grafts, with particular reference to intimal hyperplasia. Arch Surg 1988;123:691-6.

15. Campeau LC, Enjalbert M, Lesperance J, et al. The relation of risk factors to the development of atherosclerosis in saphenous vein bypass grafts and the progression of disease in the native circulation. N Engl J Med 1984;311:1329-32.

16. Angelini GD, Bryan AJ, Williams HMJ, Morgan R, Newby AC. Distension promotes platelet and leukocyte adhesion and reduces short-term patency in pig arteriovenous bypass grafts. J Thorac Cardiovasc Surg 1990;99:433-9.

17. Violaris AG, Newby AC, Angelini GD. Effects of external stenting in wall thickening in arteriovenous bypass grafts. Ann Thorac Surg 1993;55:667-71.

18. Darby I, Skalli O, Gabbiani G. Smooth muscle actin is transiently expressed by myofibroblasts during experimental wound healing. Lab Invest 1990;63:21-9.

19. Dilley RJ, McGeachie JK, Tennant M. The role of cell proliferation and migration in the development of a neointimal layer in veins grafted into arteries, in rats. Cell Tissue Res 1992;269:281-7.

20. Zwolak RM, Adams MC, Clowes AW. Kinetics of vein graft hyperplasia: association with tangential stress. J Vasc Surg 1987;5:126-36.

21. Grinnell F. Fibroblasts, myofibroblasts, and wound contraction. J Cell Biol 1994;124:401-4.

22. Shi Y, O'Brien JE, Ala-Kokko L, Chung WS, Mannion JD, Zalewski A. The origin of extracellular matrix synthesis during coronary repair. Circulation 1997;95:997-1006.

23. Schwartz SM, Reidy MR, Clowes AW. Kinetics of atherosclerosis, a stem cell model. Ann N Y Acad Sci 1985;454:292-4.

24. IP J, Fuster V, Badimon J, Taubman M, Chesebro J. Syndromes of accelerated atherosclerosis: role of vascular injury and smooth muscle proliferation. J Am Coll Cardiol 1990;15:1667-87.

25. Holifield B, Helgason T, Jemelka S, et al. Differentiated vascular myocytes: Are they involved in neointimal formation? J Clin Invest 1996;97:814-25.

26. Schmitt-Graff A, Desmoulier A, Gabbiani G. Heterogeneity of myofibroblast phenotypic features: an example of fibroblast cell plasticity. Virchow Arch B Cell Pathol Incl Mol Pathol 1994;425:3-24.

27. Shi Y, O'Brien JE Jr, Fard A, Zalewski A. Transforming growth factor $\beta_{1}$ expression and myofibroblast formation during arterial repair. Arterioscler Thromb Vasc Biol 1996;16: 1298-309.

28. Clowes AW, Schwartz SM. Significance of quiescent smooth muscle migration in the injured rat carotid artery. Circ Res 1985;56:139-45.

29. Stemerman MB, Ross R. Experimental arteriosclerosis. I. Fibrous plaque formation in primates, an electron microscope study. J Exp Med 1972;136:769-89.

30. Spaet TH, Stemerman MB, Veith FJ, Lejnieks I. Intimal injury and regrowth in the rabbit aorta: medial smooth muscle cells as a source of neointima. Circ Res 1975;36:58-70. 